\title{
Effects of Fermented Kefir as a Functional Feed Additive in Litopenaeus vannamei Farming
}

\author{
Woosik Choi ${ }^{1,+}$, Chi-Won Choi ${ }^{1,+}$, Dang-Bao Son ${ }^{1}$, Byeong-Chul Jeong ${ }^{2}$, Hee-Chang Kim ${ }^{3, *}$, \\ Hanki Lee ${ }^{1, *}$ and Joo-Won Suh ${ }^{1, *}$ \\ 1 Center for Nutraceutical and Pharmaceutical Materials, Myongji University, \\ Yongin 17058, Gyeonggi-do, Korea; woos5051@gmail.com (W.C.); xlzhvxv1004@gmail.com (C.-W.C.); \\ baoson.dang@gmail.com (D.-B.S.) \\ 2 Division of Biosciences and Bioinformatics, College of Natural Science, Myongji University, \\ Yongin 17058, Gyeonggi-do, Korea; bcjeong@mju.ac.kr \\ 3 TMC Co., Ltd., Anyang 14057, Gyeonggi-do, Korea \\ * Correspondence: jeromekim@tmc.co.kr (H.-C.K.); hklee95@mju.ac.kr (H.L.); jwsuh@mju.ac.kr (J.-W.S.); \\ Tel.: +82-2-2663-2773 (H.-C.K.); +82-31-330-6799 (H.L.); +82-31-330-6881 (J.-W.S.) \\ + These authors contributed equally to this study.
}

Received: 18 November 2020; Accepted: 26 November 2020; Published: 27 November 2020

check for updates

\begin{abstract}
Litopenaeus vannamei, known as whiteleg shrimp, is susceptible to infection by pathogenic microorganisms such as viruses and bacteria. Therefore, the prevention of infections in this shrimp is important to regulate the outbreaks of pathogenic microorganisms. In this study, we investigated the effects of kefir as a functional feed additive on innate immunity, survival against WSSV (White Spot Syndrome Virus) and productivity of L. vannamei. As a result, the treatment of kefir could upregulate six of seven genes crucial for innate immunity of L. vannamei. Also, the treatment of kefir directly improved the survival rate of L. vannamei against WSSV infection. Finally, in order to determine whether kefir can improve the productivity of shrimp, we carried out field tests in three aquaculture farms in South Korea. The weight of shrimp fed kefir was increased by $120 \%$ as well as the length, compared with that of the control group. These results demonstrate that kefir can be utilized as a functional feed additive to improve both innate immunity and productivity of L. vannamei in shrimp farming with no use of antibiotics.
\end{abstract}

Keywords: fermented kefir; Litopenaeus vannamei; innate immunity; survival rate against WSSV; productivity; functional feed additive

\section{Introduction}

Litopenaeus vannamei, known as whiteleg shrimp, is an important aquaculture species in the Asia-Pacific region because this region is the largest producer contributing to nearly $80 \%$ of the value and volume of the global shrimp market [1]. This shrimp can resist poor farming conditions such as enrichment of nitrogen sources, but it is susceptible to infection by viruses and bacteria, including Vibrio sp. [2,3]. These infections cause the sudden death of shrimp; the prevention of these infections is important to maintain the productivity of shrimp farming [2]. Antibiotics have been effective in preventing these infections, but there has been growing concern of serious problems such as the emergence of antibiotic-resistant microorganisms [4,5]. Therefore, the use of antibiotics in aquaculture is strictly regulated to minimize their negative effects on the environment and human health $[4,5]$. This has encouraged researchers to develop substances such as probiotics and identify medicinal herbs, as alternatives to antibiotics, to control infections in shrimp [1,6-11].

Kefir is milk fermented by kefir grains and contains beneficial microorganisms such as lactic acid bacteria, Bacillus spp., and yeast. These microorganisms have health-promoting and antimicrobial 
activities [12-14]. Furthermore, kefir as a nutraceutical has several beneficial properties such as immunological, antimicrobial, antitumor, and hypo-cholesterolemic effects in animals and humans [15]. Also, Uluköy et al. found out that juvenile rainbow trout fed with kefir increased nonspecific immune response and improved disease resistance against lactococcosis and yersiniosis [16]. However, there are few studies on the effects of fermented kefir on L. vannamei. In this study, we investigated the effects of kefir as a functional feed additive on innate immunity and productivity of L. vannamei without the use of antibiotics.

\section{Materials and Methods}

\subsection{Preparation of Lyophilized Kefir Cell Pellet}

Kefir grain used in this study was collected in a private house, South Korea. Kefir grains were inoculated in $4 \%(w / v)$ whole fat milk medium and cultivated at $30{ }^{\circ} \mathrm{C}$ for 2 days without agitation. For main fermentation, we developed the medium based on de Man, Rogosa and Sharpe (MRS); yeast extract-peptone-dextrose (YPD); and nutrient broth (NB) media. To determine the optimum conditions for kefir fermentation, we modified the composition of glucose, whey protein, and dipotassium phosphate in the medium, and inoculation size of seed culture. The main fermentation of kefir was carried out in $300 \mathrm{~L}$ working volume of a $500 \mathrm{~L}$ fermentor at $30^{\circ} \mathrm{C}$ for $1 \mathrm{~d}$. For fermentation, sterilized air was supplied at $2 \mathrm{vvm}$ in the fermentor, and the mixing rate was maintained at $200 \mathrm{rpm}$ using an impeller. After fermentation, the total cells were harvested by continuous centrifugation with $8000 \mathrm{rpm}$ and the cell pellet was mixed with $20 \%(w / v)$ sterilized skim milk solution. Thereafter, this mixture was lyophilized for 3 days. To determine the number of lactic acid bacteria, Bacillus spp., and yeast cells in the lyophilized sample, viable colonies were counted. Briefly, the sample was serially diluted to $0.85 \%$ with sterilized saline solution, and $100 \mu \mathrm{L}$ of the diluted sample was spread on MRS agar for lactic acid bacteria, NB agar for Bacillus spp., and YPD agar for yeast culture. After incubation at $30^{\circ} \mathrm{C}$ for 1 day, the colonies were counted.

\subsection{Monitoring the Expression Level of Genes Related to Innate Immunity in L. vannamei after Treatment with Kefir}

For this experiment, we prepared eight cages controlled by recirculating aquaculture system and transferred $30 \mathrm{~L}$. vannamei into each cage. Thereafter, feed was supplied at $3 \%(w / w)$ of the total weight of shrimps in each cage three times per day. Furthermore, lyophilized kefir was supplied at $0.2 \%(w / w)$, $0.4 \%(w / w)$, and $0.8 \%(w / w)$ of the weight of feed supplied on 1 day. Lyophilized kefir was fed one time per day. The treatment was carried out for 30 days. The number of lactic acid bacteria, Bacillus spp., and yeast in lyophilized kefir was $5.6 \times 10^{9}, 6.9 \times 10^{9}$, and $4.8 \times 10^{9} \mathrm{CFU} / \mathrm{mL}$, respectively.

After 30 days, hemolymph and hepatopancreas were isolated from all L. vannamei. To determine the total hemocyte count, the hemolymph sample was fixed in $4 \%$ formalin in fixation buffer ( $27 \mathrm{mM}$ sodium citrate, $336 \mathrm{mM} \mathrm{NaCl}, 115 \mathrm{mM}$ glucose, and $9 \mathrm{mM}$ EDTA; pH 7.0). Subsequently, the total hemocytes were counted using a Neubauer chamber. To monitor the expression level of genes related to antimicrobial peptides and the immune defense system against major pathogens (Table 1), we investigated the expression level of each gene by RT-PCR previously reported [17]. Briefly, the hepatopancreas was homogenized with liquid nitrogen, and then the total RNA was extracted using the TRIzol ${ }^{\circledR}$ Plus RNA Purification System (Thermo Fisher Scientific, Carlsbad, CA, USA). cDNA was synthesized by reverse transcription with oligo dT primer, and $0.1 \mu \mathrm{g} / \mu \mathrm{L}$ cDNA, as a template, was amplified by PCR with primers, designed using those in GenBank (https://www.ncbi.nlm.nih.gov/genbank)as described below. After PCR, the intensity of each PCR product was analyzed using the Gel Documentation System (Bio-Rad, Hercules, CA, USA) after running on $1 \%$ agarose gel. The intensity of the amplified cDNA was analyzed using ImageJ software (National Institutes of Health, Betheda, MD, USA) for quantification. 
Table 1. Information of target genes and primers for monitoring the expression level of genes related to antimicrobial peptides and the immune defense system against major pathogens.

\begin{tabular}{|c|c|c|c|}
\hline Gene & Primer & Sequence & GenBank No. \\
\hline \multirow{2}{*}{$\beta G B P$} & Forward & 5'-CGTGAGGTTCCCCAGTATGG-3' & \multirow{2}{*}{ AY249858 } \\
\hline & Reverse & 5'-TTCGGTTTGGATGGCTAAAG-3' & \\
\hline \multirow{2}{*}{ proPO } & Forward & 5'-GGAATTGTTTTACTACATGCATCAGC-3' & \multirow{2}{*}{ AY723296 } \\
\hline & Reverse & 5'-GGAACAAGTCATCCACGAGCTT-3' & \\
\hline \multirow{2}{*}{ Crustin } & Forward & 5'-ATTCTGTGCGGCCTCTTTAC-3' & \multirow{2}{*}{ AF430076 } \\
\hline & Reverse & 5'-ATCGGTCGTTCTTCAGATGG-3' & \\
\hline \multirow{2}{*}{ Penaeidin 3a } & Forward & 5'-AGCCTCACCTGCAGAGACCA-3' & \multirow{2}{*}{ Y14926 } \\
\hline & Reverse & 5'-AATCAGGATCRCAGKCTCTTCAC-3' & \\
\hline \multirow{2}{*}{ Lysozyme } & Forward & 5'-TTCGGGAAGTGCGAATTCG-3' & \multirow{2}{*}{ AY170126 } \\
\hline & Reverse & 5'-AATGGAAACCCTTGGTGAC-3' & \\
\hline \multirow{2}{*}{$S O D$} & Forward & 5'-GAGAAGAAGTTGGCTGAGCT-3' & \multirow{2}{*}{ AY486424 } \\
\hline & Reverse & 5'-ATGTTGGGTCCAGAAGATGG-3' & \\
\hline \multirow{2}{*}{ Hemocyanin } & Forward & 5'-AATGCAGCCTACTTCCGTCAG-3' & \multirow{2}{*}{ X82502 } \\
\hline & Reverse & 5'-TTATCGGGGTACACGCCATG-3' & \\
\hline \multirow{2}{*}{$\beta$-actin } & Forward & 5'-TGTGTGACGACGAAGTAGCC-3' & \multirow{2}{*}{ AF300705 } \\
\hline & Reverse & 5'-TGGTCGTGAAGGTGTAACCA-3' & \\
\hline
\end{tabular}

\subsection{Monitoring the Effect of Kefir through WSSV (White Spot Syndrome Virus) Challenge Test}

Two hundred and forty L. vannamei were used for this challenge test and it was confirmed that these shrimps were specifically pathogen free by National Institute of Fisheries Science, Rep. of Korea. We divided the total amount into four groups: negative, positive and two kefir-treated groups according to kefir concentration. Each group was subdivided into three subgroups. Each 15 shrimps were tested in a plastic aquarium $(1 \mathrm{~m} \times 1 \mathrm{~m} \times 0.7 \mathrm{~m})$. Average weight of shrimps for this experiment was $4.70 \mathrm{~g}$. Before infection of WSSV, all shrimps were acclimated for 7 days in plastic aquarium.

To prepare the WSSV filtrate, we obtained dead shrimps by infection of WSSV and homogenized the infected organ of dead shrimp in TNE buffer $(50 \mathrm{mM}$ Tris- $\mathrm{HCl}, 0.1 \mathrm{M} \mathrm{NaCl}$, and $1 \mathrm{mM}$ EDTA, $\mathrm{pH}$ 7.5). Next, the homogenate was centrifuged at $6000 \mathrm{rpm}$ and $4{ }^{\circ} \mathrm{C}$ for $15 \mathrm{~min}$ and the supernatant was centrifuged again at $12,000 \mathrm{rpm}$ and $4{ }^{\circ} \mathrm{C}$ for $15 \mathrm{~min}$ for $30 \mathrm{~min}$. The final supernatant was filtrated by $0.45 \mu \mathrm{m}$ syringe filter. To determine LD50 as the dose used for this experiment, we injected $0.1 \mathrm{~mL}$ of $10^{-2}, 10^{-3}, 10^{-4}$, and $10^{-5}$ diluted filtrate in the dorsal body part of one shrimp and checked that LD50 of filtrate was $10^{-4}$ diluted filtrate. The infection of WSSV was carried out by the injection of the $0.1 \mathrm{~mL}$ of $10^{-4}$ diluted filtrate into the dorsal body of all shrimps without a negative control group. In the negative control group, the buffer was injected instead of the filtrate. After injection, we monitored the number of dead shrimp day by day for 15 days. The feeding for this experiment was carried out like described above.

For this experiment, the temperature of all of aquariums had been kept at $28{ }^{\circ} \mathrm{C}$ and all aquariums were aerated by air blower. The range of parameters of water quality like dissolved oxygen, $\mathrm{pH}$, total ammonium nitrogen, and nitrate was kept on according to Holmström (2003) [5]. Survival rate by kefir treatment was calculated by Kaplan-Meier survival analysis provided in Prism 8 (GraphPad Software, San Diego, CA, USA).

\subsection{Monitoring Weight Gain in L. vannamei after Treatment with Kefir through Field Test}

For the field test, three shrimp farms located in Taean-Gun, Chungcheongnam-do, South Korea, were selected. The shrimp were treated with lyophilized kefir one time per week from May to October. The amount of lyophilized kefir in a tank of $1 \mathrm{~m}$ depth was $10 \mathrm{~kg} / \mathrm{ha}$, and the number of lactic acid bacteria, Bacillus spp., and yeast in lyophilized kefir was $5.6 \times 10^{9}, 6.9 \times 10^{9}$, and $4.8 \times 10^{9} \mathrm{CFU} / \mathrm{mL}$, 
respectively. To monitor the length and weight of the shrimp, we collected 100 shrimps before transfer to the main farm, at July, and at the end of farming. We measured the length and weight of the shrimps collected. The occurrence of significant differences in the average weight by treatment of lyophilized kefir was tested using Student's $t$-test.

\subsection{Statistical Analysis}

Statistical analyses were accomplished using SPSS 22.0 (IBM Corp., Armonk, NY, USA). The obtained data were analyzed by the paired $t$-test for evaluating the association and significance between variables. A $p$ value $<0.05$ indicated significance.

\section{Results}

\subsection{Optimization of Culture Conditions for the Growth of Kefir}

For the main fermentation of kefir, seed culture of kefir was carried out in whole fat milk medium for 2 days at $30{ }^{\circ} \mathrm{C}$ without agitation. To optimize the conditions of the main culture, we tested several parameters such as the content of glucose as a carbon source, whey protein as a nitrogen source, and dipotassium phosphate as a phosphate source, and the size of seed inoculated. The colony forming unit (CFU) of lactic acid bacteria, Bacillus spp., and yeast increased at $2 \%$ of glucose, $1 \%$ of whey protein and $0.02 \%$ and $0.1 \%$ of dipotassium phosphate, compared to other concentrations of nutrients (Figure $1 \mathrm{~A}-\mathrm{C}$ ). In addition, we examined how the CFU of these microorganisms changed according to the size of inoculation of seed culture. Interestingly, the CFUs were the maximum with $2 \%$ inoculation of seed culture, rather than 10\% (Figure 1D). Based on these results, we finally chose the optimal content of glucose, whey protein, and dipotassium phosphate, and size of inoculum (Table 2).
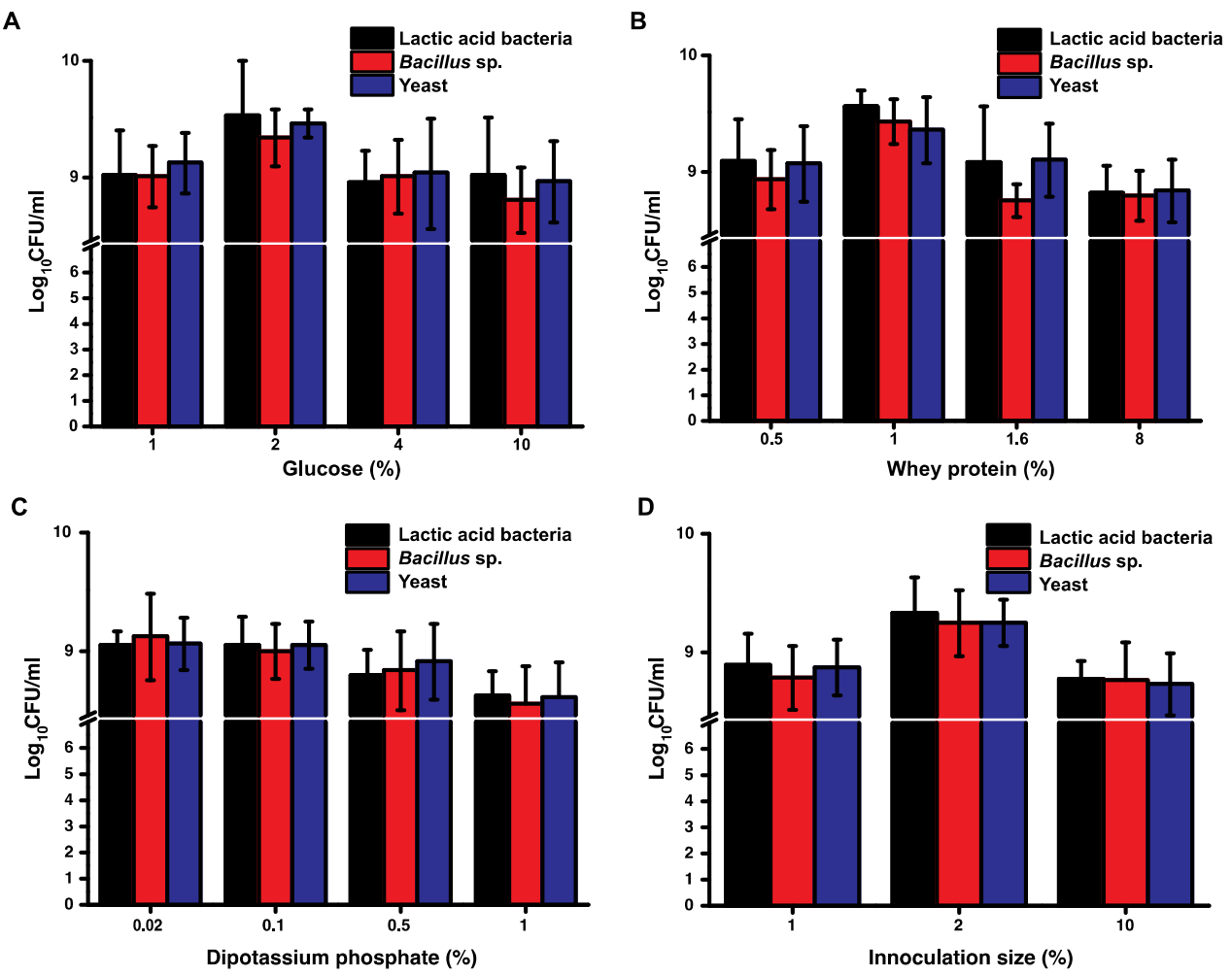

Figure 1. Proportion of lactic acid bacteria, Bacillus spp., and yeast in kefir according to culture conditions. (A) The proportion of lactic acid bacteria, Bacillus spp., and yeast in kefir by glucose content. (B) The proportion of lactic acid bacteria, Bacillus spp., and yeast in kefir by whey protein content. (C) The proportion of lactic acid bacteria, Bacillus spp., and yeast in kefir by dipotassium phosphate content. (D) The proportion of lactic acid bacteria, Bacillus spp., and yeast in kefir by inoculation size. 
Table 2. The optimized medium condition for kefir fermentation.

\begin{tabular}{cc}
\hline Component & Composition $(\%, w / v)$ \\
\hline Glucose & 2 \\
Whey protein & 1 \\
Dipotassium phosphate & 0.02 \\
Yeast extract & 2 \\
Ammonium sulfate & 0.1 \\
$\mathrm{MgSO}_{4}$ & 0.01 \\
$\mathrm{MnSO}_{4}$ & 0.05 \\
Inoculation size & 2 \\
\hline
\end{tabular}

\subsection{Effect of Kefir on the Innate Immunity of L. vannamei}

To monitor the effect of kefir on the innate immunity of L. vannamei, we treated lyophilized kefir with different doses. After 30 days of treatment, the total hemocytes in the hemolymph of L. vannamei were counted. Next, we examined the expression level of immune-related genes such as beta-glucan binding protein $(\beta G B P)$, prophenoloxidase (proPO), crustin, peaneidin $3 a$, lysozyme, superoxide dismutase (SOD), and hemacyanin in the hepatopancreas of L. vannamei. The treatments of kefir did not change the number of total hemocytes (Table 3). However, the expression of immune-related genes was substantially upregulated after treatment of kefir (Figure 2). The expression of $\beta$ GBP was upregulated fourfold in the group treated with $0.8 \%$ lyophilized kefir compared with that in the control group (Figure 2). Moreover, the expression of proPO, lysozyme, and SOD was substantially upregulated by lyophilized kefir treatment in a dose-dependent manner (Figure 2). The treatment of lyophilized kefir strongly induced the expression of genes encoding crustin and penaedin-3a by threefold compared with the control (Figure 2). These results indicate that kefir can contribute to the enhancement of the immune system in L. vannamei by upregulating the expression of immune-related genes and not cellular immunity by increasing hemocytes.

Table 3. The number of total hemocytes in L. vannamei by treatment of fermented kefir.

\begin{tabular}{cc}
\hline Kefir Treated $(\mathbf{\%})$ & Number of Total Hemocytes $(\times \mathbf{1 0} \mathbf{7} \mathbf{m L})$ \\
\hline 0 & $7.53 \pm 0.30$ \\
0.20 & $7.46 \pm 0.11$ \\
0.40 & $7.40 \pm 0.2$ \\
0.80 & $7.6 \pm 0.2$ \\
\hline
\end{tabular}

\subsection{Effect of Kefir in L. vannamei against WSSV Infection}

After infection of WSSV filtrate, the number of dead shrimps immediately increased and the survival rate at the end of this experiment was calculated to be $33.33 \%$ in the positive group (Figure 3 ). In the case of the $0.2 \%$ kefir-treated group, the death rate was retarded early, compared to the positive group. However, the survival rate was the same at the end of the experiment (Figure 3). Meanwhile, in the case of the $0.8 \%$ kefir-treated group, the survival rate was dramatically improved and calculated to be $56.8 \%$ at the end of this experiment. This result means that the enhancement of innate immunity of $L$. vannamei by treatment of kefir can increase the survival rate against WSSV infection.

\subsection{Effect of Kefir on Productivity of L. vannamei}

In the development of a functional feed additive for shrimp farming, the improvement of shrimp productivity is an important aspect. Therefore, to examine whether kefir can improve the productivity of L. vannamei, we treated lyophilized kefir in three farms in South Korea after transfer to the main pond for 6 months; we measured the weight of shrimp before transfer to the main pond, and at 3 and 6 months after transfer. The shrimps in the group treated with lyophilized kefir were longer than those in the control group (Figure 4A-D). Furthermore, the average weight of L. vannamei in the group 
treated with lyophilized kefir increased by up to $120 \%$ compared with that of L. vannamei in the control group (Figure 4E-G). The increase in both length and weight of shrimp in the group treated with lyophilized kefir was observed in all three farms. These results indicate that the supplementation of kefir can improve the utilization of feed to increase the length and weight of L. vannamei.

A

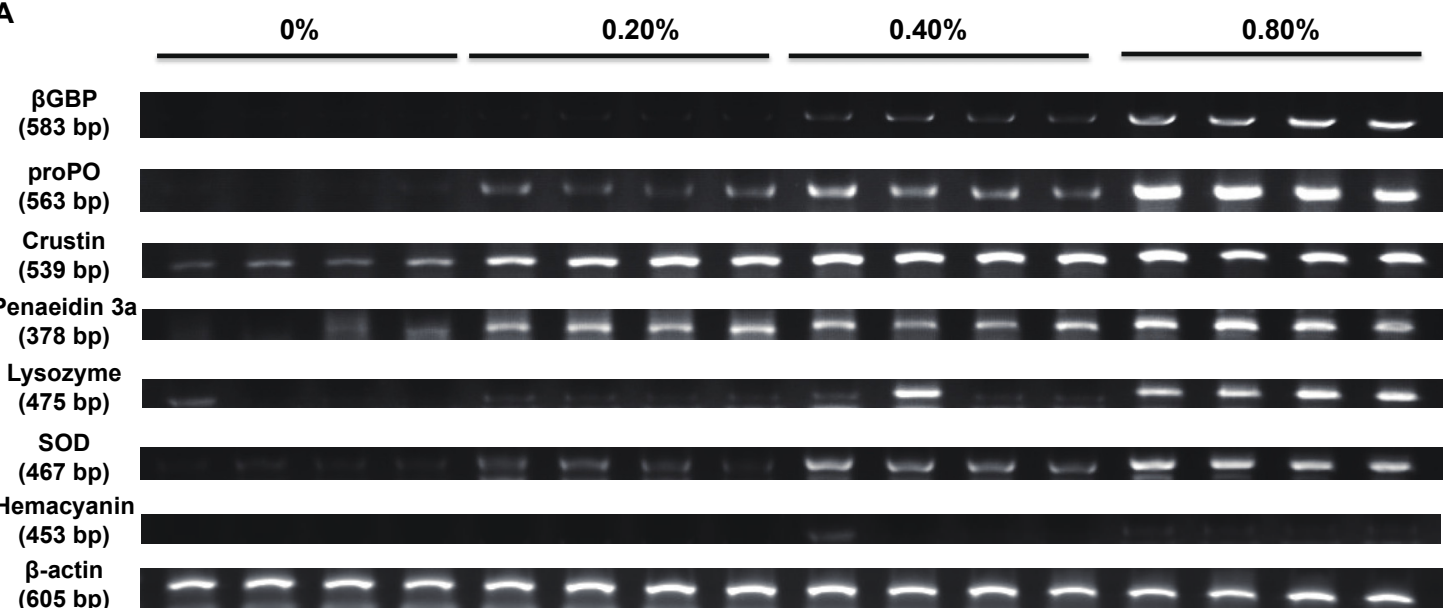

B
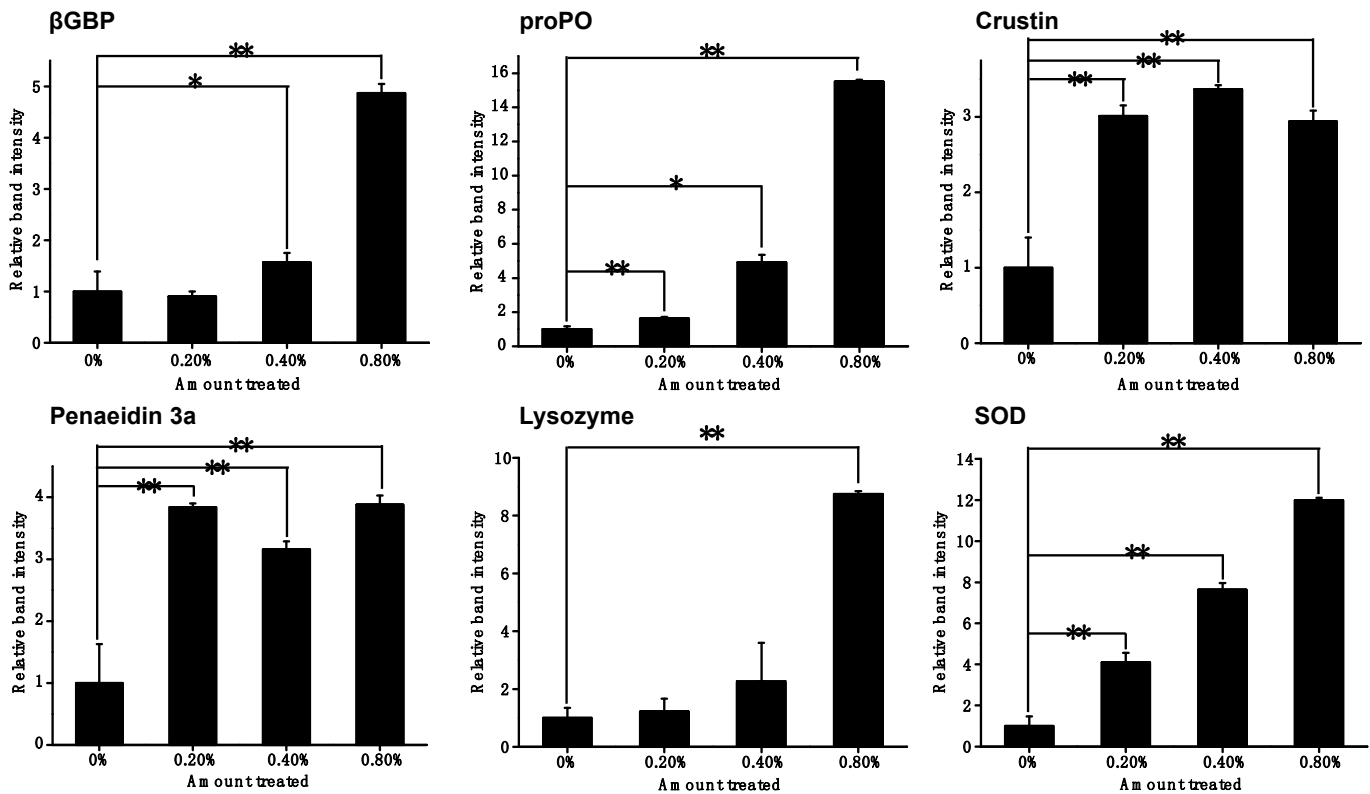

Hemocyanin

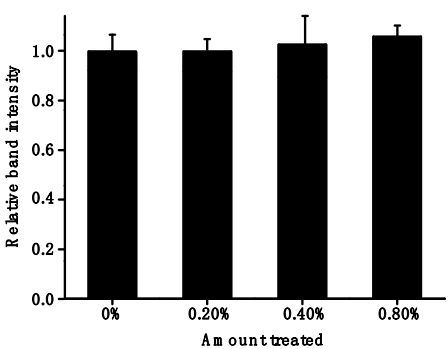

Figure 2. Transcription level of genes related to innate immunity in L. vannamei after treatment with kefir. (A) The amplified cDNA genes related to innate immunity in L. vannamei after treatment with kefir. (B) Quantification of the amplified cDNA genes related to innate immunity in L. vannamei using ImageJ. For quantification of the amplified cDNA genes, the intensity of the amplified cDNA in four wells was averaged and normalized by dividing with amplified cDNA intensity of the non-treated group. ${ }^{*} p<0.05$ and ${ }^{* *} p<0.01$, accessed using the paired $t$ test. 


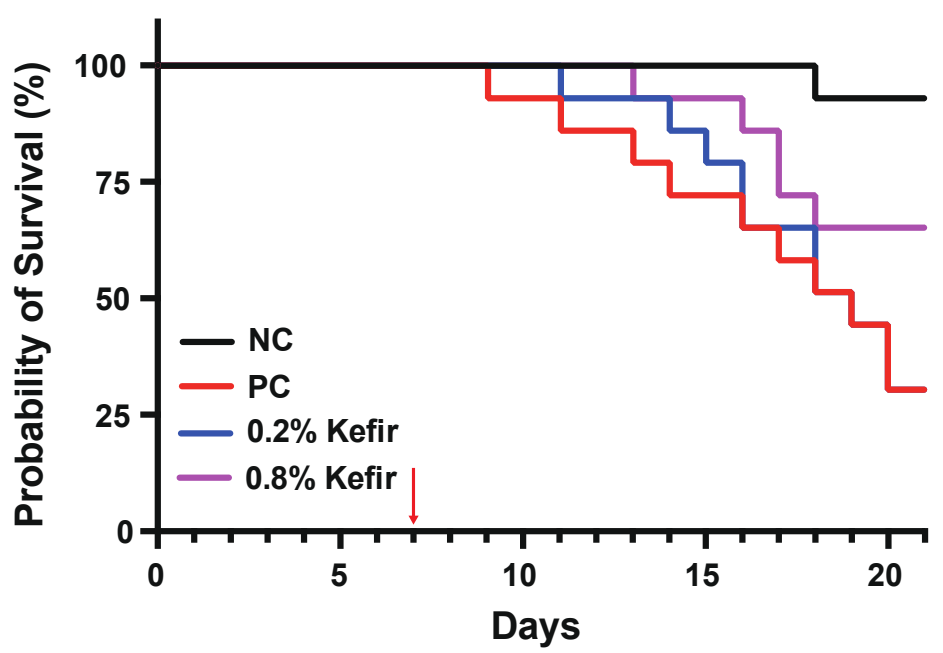

Figure 3. Survival rate of L. vannamei against WSSV infection according to treatment of kefir. NC and PC indicate negative and positive control group, respectively. Red arrow indicates the day when WSSV filtrate was injected except for the negative control group.

A

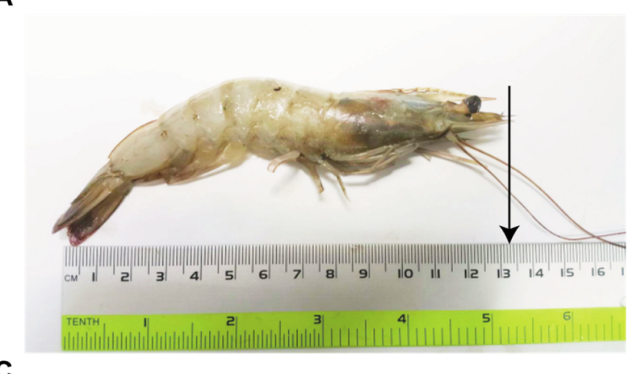

C

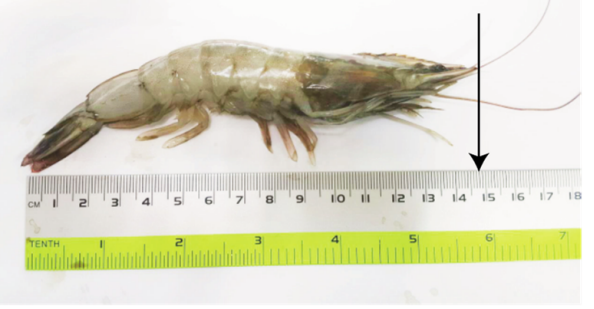

E

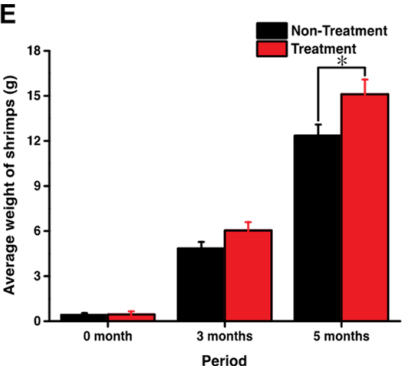

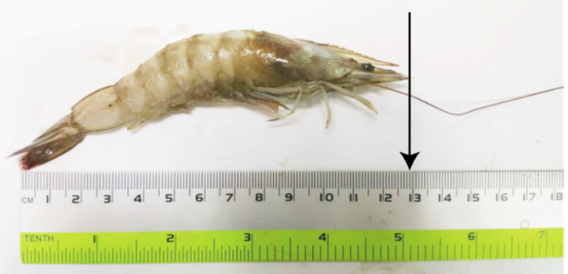

D

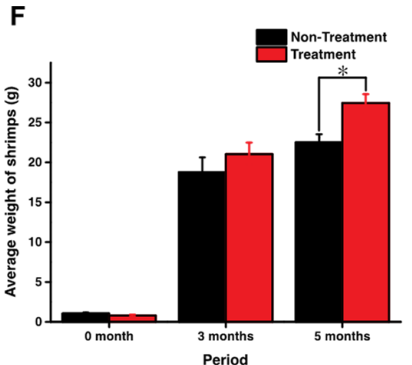

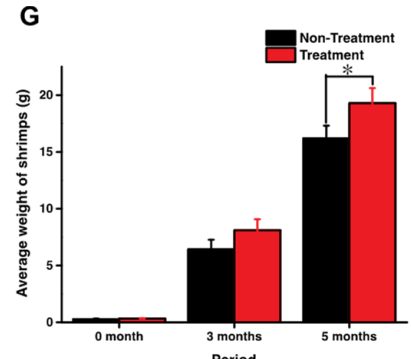

Figure 4. The growth of L. vannamei after treatment with kefir. (A,B) Representative images of the length of L. vannamei in the non-treated group. (C,D) Representative images of the length of L. vannamei in the kefir-treated group. Black arrows indicate the end of head of L. vannamei. (E) The average weight of L. vannamei after treatment with kefir in shrimp farm \#01. (F) The average weight of L. vannamei after treatment with kefir in shrimp farm \#02. (G) The average weight of L. vannamei after treatment with kefir in shrimp farm \#03. The average weight of L. vannamei was calculated by the average weight of 100 L. vannamei individuals. ${ }^{*} p<0.05$, accessed using the paired $t$ test. 


\section{Discussion}

The production of this shrimp is approximately 50 ton/ha/crop, which exceeds the production of Penaeus monodon, another popular shrimp species [18]. It has been reported that L. vannamei is highly tolerant to a wide range of salinity levels and requires a relatively low protein feed [18]. Furthermore, this shrimp can grow with high stocking densities and at low temperatures of up to $15^{\circ} \mathrm{C}$ [19]. Even with these advantages, L. vannamei is prone to be infected by viruses such as Taura syndrome virus (TSV), white spot syndrome virus (WSSV), and yellow head virus (YHV), and pathogenic bacteria such as Vibrio parahaemolyticus [19]. Moreover, high-density farming of this shrimp that produces yields of 20,000 to $100,000 \mathrm{~kg} / \mathrm{ha} /$ year results in the outbreak of infection by viruses and pathogenic bacteria because of eutrophication by unconsumed feeds and lots of shrimp feces [4]. Treatment with antibiotics is one of the approaches used to prevent these infections, but their use is strictly restricted because antibiotics can cause the development of antibiotic resistance among pathogens $[4,5]$. Thus, there is a need for alternatives to antibiotics in shrimp farming.

It has been reported that kefir consists of lactic acid bacteria, Bacillus spp., and yeast that play a role as probiotics [20], and thus, it has various probiotic properties [21]. Furthermore, the effect of probiotics as an alternative to antibiotics has been studied in shrimp farming [1,6,7]. Therefore, in this study, we explored the effect of kefir as a functional feed additive in shrimp farming to improve the immune system and productivity of L. vannamei with no use of antibiotics. We treated lyophilized kefir and determined the number of hemocyte and expression level of genes related to the innate immune system of L. vannamei. In L. vannamei, hemocytes play pivotal roles in pattern-recognition system, phagocytosis, proPO-activating system, encapsulation, nodule formation, antimicrobial peptide release, and lysozyme activity [2]. In this study, lyophilized kefir did not directly affect the count of hemocytes, but it substantially upregulated the expression of the $\beta \mathrm{GBP}$, proPO, crustin, peaneidin $3 a$, lysozyme, and SOD genes. $\beta \mathrm{GBP}$ is a pattern-recognition protein and proPO participates in the proPO cascade [22]. Furthermore, crustin and peaneidin 3a are antimicrobial peptides [23]. Lysozyme and SOD are known to participate in the post-phagocytosis process to remove toxic materials during phagocytosis [2]. Also, in WSSV challenge experiment, we observed that the survival rate of L. vannamei-treated $0.8 \%$ kefir was obviously improved, compared to positive control and the $0.2 \%$ kefir-treated group. So, it is shown that the enhancement of innate immunity of L. vannamei directly can improve the survival of these shrimp against WSSV infection.

In terms of economic status, the use of functional feed additive might increase the cost of management; therefore, an improvement in shrimp productivity is one of the important factors when choosing a functional feed additive [7]. In this study, we carried out a field test in three farms in South Korea. During farming, we monitored the weight of shrimps before the transfer of shrimp to the main pond and after 3 months of feeding and harvest of shrimp. After 3 months of feeding, the average weight of shrimp was higher than that of the control group shrimp; at harvest, the average weight of shrimp treated with lyophilized kefir increased by $120 \%$ compared with that of the control group. This suggests that multiple bacteria in kefir can promote the growth of L. vannamei. Based on these results, we conclude that kefir might be a promising feed additive for both enhancement of the immune defense system and improvement of productivity of L. vannamei without treatment of antibiotics.

Author Contributions: H.-C.K., H.L., and J.-W.S. designed the research and conducted all experiments. W.C. and C.-W.C. mainly carried out field test and monitored the expression level of genes and weight of shrimps. D.-B.S. and B.-C.J. carried out kefir fermentation, lyophilized kefir preparation, and viable cell counting in the sample. H.L. wrote the manuscript. All authors discussed the results and commented on the manuscript. All authors have read and agreed to the published version of the manuscript.

Funding: This work was supported by the Cooperative Research Program for Agriculture Science \& Technology Development (Project No. 01128905) from the Rural Development Administration, South Korea.

Conflicts of Interest: The authors declare no conflict of interest. 


\section{References}

1. Van Hai, N.; Fotedar, R. A Review of Probiotics in Shrimp Aquaculture. J. Appl. Aquac. 2010, 251-266. [CrossRef]

2. Lin, Y.C.; Chen, J.C.; Siti, S.N.; Wan, W.Z.; Awangku, A.S.; Cheng, S.Y.; Hsu, C.H. Modulation of Innate Immunity and Gene Expressions in White Shrimp Litopenaeus Vannamei Following Long-Term Starvation and Re-Feeding. Results Immunol. 2012, 2, 148-156. [CrossRef]

3. Mohney, L.L.; Lightner, D.V.; Bell, T.A. An Epizootic of Vibriosis in Ecuadorian Pond-Reared Penaeus Vannamei Boone (Crustacea: Decapoda). J. World Aquac. Soc. 1994, 25, 116-125. [CrossRef]

4. Bermdez-Almada, M.C.; Espinosa-Plascenci, A. The Use of Antibiotics in Shrimp Farming. In Health and Environment in Aquaculture; IntechOpen Limited: London, UK, 2012. [CrossRef]

5. Holmström, K.; Gräslund, S.; Wahlström, A.; Poungshompoo, S.; Bengtsson, B.E.; Kautsky, N. Antibiotic Use in Shrimp Farming and Implications for Environmental Impacts and Human Health. Int. J. Food Sci. Technol. 2003, 38, 255-266. [CrossRef]

6. Farzanfar, A. The Use of Probiotics in Shrimp Aquaculture. FEMS Immunol. Med. Microbiol. 2006, 149-158. [CrossRef] [PubMed]

7. Ninawe, A.S.; Selvin, J. Probiotics in Shrimp Aquaculture: Avenues and Challenges. Crit. Rev. Microbiol. 2009, 35, 43-66. [CrossRef] [PubMed]

8. Kumar, V.; Roy, S.; Meena, D.K.; Sarkar, U.K. Application of Probiotics in Shrimp Aquaculture: Importance, Mechanisms of Action, and Methods of Administration. Rev. Fish. Sci. Aquac. 2016, 342-368. [CrossRef]

9. Sivasankar, P.; Santhiya, A.V.; Kanaga, V. A Review on Plants and Herbal Extracts against Viral Diseases in Aquaculture. J. Med. Plants Stud. 2015, 3, 75-79.

10. Immanuel, G.; Vincybai, V.C.; Sivaram, V.; Palavesam, A.; Marian, M.P. Effect of Butanolic Extracts from Terrestrial Herbs and Seaweeds on the Survival, Growth and Pathogen (Vibrio Parahaemolyticus) Load on Shrimp Penaeus Indicus Juveniles. Aquaculture 2004, 236, 53-65. [CrossRef]

11. Yogeeswaran, A.; Velmurugan, S.; Punitha, S.M.J.; Babu, M.M.; Selvaraj, T.; Kumaran, T.; Citarasu, T. Protection of Penaeus Monodon against White Spot Syndrome Virus by Inactivated Vaccine with Herbal Immunostimulants. Fish Shellfish Immunol. 2012, 32, 1058-1067. [CrossRef]

12. Bourrie, B.C.T.; Willing, B.P.; Cotter, P.D. The Microbiota and Health Promoting Characteristics of the Fermented Beverage Kefir. Front. Microbiol. 2016, 7, 647. [CrossRef] [PubMed]

13. Leite, A.M.D.O.; Miguel, M.A.L.; Peixoto, R.S.; Rosado, A.S.; Silva, J.T.; Paschoalin, V.M.F. Microbiological, Technological and Therapeutic Properties of Kefir: A Natural Probiotic Beverage. Braz. J. Microbiol. 2013, 341-349. [CrossRef] [PubMed]

14. Laureys, D.; De Vuyst, L. Microbial Species Diversity, Community Dynamics, and Metabolite Kinetics of Water Kefir Fermentation. Appl. Environ. Microbiol. 2014, 80, 2564-2572. [CrossRef] [PubMed]

15. Liu, J.R.; Chen, M.J.; Lin, C.W. Antimutagenic and Antioxidant Properties of Milk-Kefir and Soymilk-Kefir. J. Agric. Food Chem. 2005, 53, 2467-2474. [CrossRef]

16. Uluköy, G.; Metin, S.; Kubilay, A.; Güney, Ş.; Yıldırım, P.; Güzel-Seydim, Z.; Kok-Tas, T.; Gümüş, E. The Effect of Kefir as a Dietary Supplement on Nonspecific Immune Response and Disease Resistance in Juvenile Rainbow Trout, Oncorhynchus Mykiss (Walbaum 1792). J. World Aquac. Soc. 2017, 48, 248-256. [CrossRef]

17. Wang, Y.C.; Chang, P.S.; Chen, H.Y. Tissue Expressions of Nine Genes Important to Immune Defence of the Pacific White Shrimp Litopenaeus Vannamei. Fish Shellfish Immunol. 2007, 23, 1161-1177. [CrossRef]

18. Thakur, K.; Patanasatienkul, T.; Laurin, E.; Vanderstichel, R.; Corsin, F.; Hammell, L. Production Characteristics of Intensive Whiteleg Shrimp (Litopenaeus Vannamei) Farming in Four Vietnam Provinces. Aquac. Res. 2018, 49, 2625-2632. [CrossRef]

19. Li, E.; Wang, X.; Chen, K.; Xu, C.; Qin, J.G.; Chen, L. Physiological Change and Nutritional Requirement of Pacific White Shrimp Litopenaeus Vannamei at Low Salinity. Rev. Aquac. 2017, 57-75. [CrossRef]

20. Shi, X.; Chen, H.; Li, Y.; Huang, J.; He, Y. Effects of Kefir Grains on Fermentation and Bioactivity of Goat Milk. Acta Univ. Cibiniensis Ser. E Food Technol. 2018, 22, 43-50. [CrossRef]

21. Guzel-Seydim, Z.B.; Kok-Tas, T.; Greene, A.K.; Seydim, A.C. Review: Functional Properties of Kefir. Crit. Rev. Food Sci. Nutr. 2011, 261-268. [CrossRef] 
22. Amparyup, P.; Charoensapsri, W.; Tassanakajon, A. Prophenoloxidase System and Its Role in Shrimp Immune Responses against Major Pathogens. Fish Shellfish Immunol. 2013, 34, 990-1001. [CrossRef]

23. Tassanakajon, A.; Somboonwiwat, K. Antimicrobial Peptides from the Black Tiger Shrimp Penaeus Monodon-A Review. In Dissease in Asian Aquaculture VII; Asian Fisheries Society: Kuala Lumpur, Malaysia, 2011; pp. 229-240.

Publisher's Note: MDPI stays neutral with regard to jurisdictional claims in published maps and institutional affiliations.

(C) 2020 by the authors. Licensee MDPI, Basel, Switzerland. This article is an open access article distributed under the terms and conditions of the Creative Commons Attribution (CC BY) license (http://creativecommons.org/licenses/by/4.0/). 